\title{
RECENSIÓN
}

\section{VACUNAS PREVENTIVAS. PRINCIPIOS Y APLICACIONES}

\author{
Lluís Salleras Sanmartí \\ Año 1998 \\ Masson. Barcelona \\ ISBN 84-458-0660-2 \\ 739 páginas.
}

Recensión: Cristina Pérez Andrés. Subdirección General de Epidemiología, Promoción y Educación para la Salud. Dirección General de Salud Pública. Ministerio de Sanidad y Consumo.

El libro Vacunas preventivas. Principios y aplicaciones, cditado por Lluis Salleras Sanmartí, es un verdadero tratado sobre las vacunas, que incluye una extensa introducción sobre el sistema inmunitario humano y las clases de vacunas existentes, así como sobre los conceptos de salud pública de interés en este terreno, como son los relativos a la inmunidad individual y la de grupo, los de vacunas sistemáticas y no sistemáticas y, con ello, a los de los criterios necesarios para el diseño de programas de vacunación para la comunidad.

En los diferentes capítulos de la obra (Principios básicos; Vacunas sistemáticas y no sistemáticas; Aspectos prácticos de las vacunaciones; Planificación y evaluación de los programas de vacunaciones; Vacunaciones en la eliminación de las enfermedades transmisibles y Perspectivas futuras de nuevas vacunas) colaboran 81 especialistas de la salud pública, la microbiología y la pediatría, que trabajan en la Administración sanitaria española, en la Universidad, en la atención primaria y en los hospitales o en la Organización Mundial de la Salud.

Además de quedar expuesto el calendario de vacunaciones recomendado por el Ministerio de Sanidad y Consumo, en relación a las enfermedades vacunables, se comenta no sólo la prevención primaria mediante la vacuna que se detalla, sino una descripción completa de la historia de la enfermedad transmisible que previene, sus características epidemiológicas, la etiopatogenia, la clínica y el tratamiento, así como las bases de salud pública necesarias para evaluar la magnitud del problema causado por dicha enfermedad, y la descripción y diseño de los programas necesarios para la prevención y/o control de la misma.

Cada vacuna está descrita a nivel específico, quedando revisada su inmunogenicidad y los factores que influyen en la misma, tanto por parte del receptor como de la propia vacuna; también la duración de la inmunidad que produce y la necesidad de dosis de recuerdo, así como sus posibles efectos secundarios.

No sólo se comentan las vacunaciones del calendario vacunal, sino otras de aplicación no sistemática. Quedan así estudiadas las vacunas antidiftérica, antitetánica, antihepatitis A y antihepatitis $B, \ldots$ hasta un total de 27 vacunas, entre ellas, al hilo del tema monográfico que se ha tratado en este número de la Revista Española de Salud Pública, la vacuna antimeningocócica.

Aunque la información sobre la epidemia de enfermedad meningocócica de la tempo- 
rada invernal 96-97 no está incluida en el capítulo correspondiente, ya que debió de coincidir con la elaboración de este volumen, ya se señala en el mismo el aumento progresivo que se iba produciendo de los casos de enfermedad meningocócíca debidos al serogrupo $\mathrm{C}$ en lugar del $\mathrm{B}$, que era el más frecuente hasta entonces en nuestro país, pasando el serotipo C del $6 \%$ en 1985 al $34,1 \%$ en 1994. En 1985 el serogrupo B suponía el $92,5 \%$ de los casos y, dado que para cl mismo no existía ninguna vacuna que produjera el aumento de anticuerpos protectores, no se planteaba ningún problema de vacunación de la población durante sus epidemias.

Sin embargo, en la epidemia de la temporada invernal de 1996/97, la mayoría de los casos fueron producidos por el serogrupo $\mathrm{C}$ del meningococo, y el hecho de existir vacuna para el mismo, aunque no en nuestro país por las razones antes expuestas relativas a su frecuencia, originó las reacciones contrarias y encontradas por parte de la administración sanitaria y los ciudadanos. Los primeros mantenían los criterios técnicos de aplicación de la vacuna, relativos a la eficacia de la misma, la efectividad en función de la edad de los sujetos vacunados, así como a la duración de la inmunogenicidad conseguida y al efecto negativo o positivo de una segunda dosis de recuerdo. Todos estos temas son tratados en este libro en el capítulo relativo a la vacuna antimeningocócica, el cual dispondrá de material muy útil para su revisión cuando se publiquen los resultados de los trabajos que en este número de la Revista Española de Salud Pública sobre enfermedad meningocócica quedan planteados para investigar, ya que algunos de ellos se refieren, precisamente, a la eficacia y efectividad de las campañas de vacunaciones llevadas a cabo en la temporada invernal 97/98, en diferentes Comunidades Autónomas.

Como se ha señalado desde el principio de esla recensión, este libro sobre vacunaciones es útil no sólo para el conocimiento de las mismas desde el punto de vista clínico sino, también, desde el punto de vista de la salud pública y la administración sanitaria, de cara al diseño de programas de vacunaciones, la evaluación de los mismos y las posibilidades de erradicación y control de una enfermedad transmisible desde la perspectiva de la vacunación. Por lo que de él pueden aprovechar su contenido tanto el personal sanitario que trabaja en el nivel clínico, bien sea de atención primaria u hospitalario, como los trabajadores de la salud pública en los niveles de planificación, programación y evaluación. 